\title{
Substructural investigations, Raman, and FTIR spectroscopies of nanocrystalline ZnO films deposited by pulsed spray pyrolysis
}

\author{
O. Dobrozhan ${ }^{*, 1,2}$, A. Opanasyuk', M. Kolesnyk', M. Demydenko ${ }^{1,3}$, and H. Cheong \\ ${ }^{1}$ Sumy State University, Rymskogo-Korsakova St. 2, 40007 Sumy, Ukraine \\ ${ }^{2}$ Catalonia Institute for Energy Research IREC, Sant Adria del Besos, 08930 Barcelona, Spain \\ ${ }^{3}$ Institute of Physics, Slovak Academy of Sciences, Dubravska cesta 9, 84511 Bratislava, Slovakia \\ ${ }^{4}$ Sogang University, 35 Baekbeom-ro, Mapo-gu, Seoul 121-742, Republic of Korea
}

Received 10 May 2015, revised 9 August 2015, accepted 19 August 2015

Published online 10 September 2015

Keywords FTIR spectroscopy, pulsed spray pyrolysis, Raman spectroscopy, structure, thin films, ZnO

*Corresponding author: e-mail dobrozhan.a@gmail.com, Phone: +38 050800 9428, Fax: +38 0542334049

Nanocrystalline ZnO films were deposited onto glass substrates in the temperature range of 473-673 K using pulsed spray pyrolysis. The structural, substructural, and optical properties of the films were investigated by means of X-ray diffraction analysis, Raman scattering, and Fourier transform infrared (FTIR) spectroscopy. The effect of the substrate temperature $\left(T_{\mathrm{s}}\right)$ on the coherent scattering domain (CSD) sizes $L$, microstrains $\varepsilon$, and microstress $\sigma$ grades, and the average density of dislocations $\rho$ in the films were estimated through the broadening of X-ray lines using the Cauchy and Gauss approximations and the threefold function convolution method. The $\mathrm{ZnO}$ films grown at $T_{\mathrm{s}}=623-673 \mathrm{~K}$ possessed the highest values of $L$, and the lowest of $\varepsilon, \sigma$, and $\rho$, indicating high-crystalline quality. The Raman spectra showed peaks located at 95-98, 333-336, 415, 439-442, 572, and 578$584 \mathrm{~cm}^{-1}$, which were interpreted as $E_{2}^{\text {low }}(\mathrm{Zn}),\left(E_{2}^{\text {high }}-E_{2}{ }^{\text {low }}\right)$, $E_{1}(\mathrm{TO}), E_{2}{ }^{\text {high }}(\mathrm{O}), A_{1}(\mathrm{LO})$ and $E_{1}(\mathrm{LO})$ phonon modes of the $\mathrm{ZnO}$ wurtzite phase. The FTIR spectra showed relatively weak signals at 856,1405 , and $1560 \mathrm{~cm}^{-1}$, corresponding to the $\mathrm{C}-\mathrm{H}$ and $\mathrm{C}-\mathrm{O}$ stretching modes, in addition to the main $\mathrm{Zn}-\mathrm{O}$ mode at $475 \mathrm{~cm}^{-1}$, indicating a low content of precursor residues.
1 Introduction Over the past decade, $\mathrm{ZnO}$ has attracted considerable interest in the research community due to its unique electrical and optical properties and highthermal and chemical stability. Moreover, $\mathrm{ZnO}$ is a nontoxic, inexpensive, and relatively abundant material. $\mathrm{ZnO}$ belongs to the group of II-VI compound semiconductors and possesses a wide direct bandgap $\left(E_{\mathrm{g}}=3.37 \mathrm{eV}\right.$ at $\left.300 \mathrm{~K}\right)$ and the highest exciton binding energy $(60 \mathrm{meV})$ among binary compounds [1]. This semiconductor is a promising candidate for application in optoelectronic devices such as light-emitting diodes, ultraviolet lasers and detectors, and transparent electronics [2-4] among others. Furthermore, $\mathrm{ZnO}$ thin films are widely used in solar cells as either transparent conductive or window layer [5]. Aluminumdoped zinc oxide films (ZnO:Al, AZO) are strong alternatives to transparent conductive oxides (ITO, FTO) that are currently used in the solar cell structure [6].

$\mathrm{ZnO}$ films are prepared by various techniques, such as chemical vapor deposition [7], magnetron sputtering [8], sol-gel method [9], spray pyrolysis [10-12], etc. Among them, spray pyrolysis is a relatively simple, versatile, low cost, and non-vacuum approach to deposit large area $\mathrm{ZnO}$ thin films with controllable properties onto the substrates of different materials, including flexible ones.

In thin film solar cells $[13,14]$, the main function of the conductive and window layers is the transmission of a greater number of photons from incident solar radiation. $\mathrm{ZnO}$ thin films, which are used for this purpose, should be in a single phase and have high transmittance and electrical conductivity, low microstresses and microstrains grades, and a small dislocation density. Increased transmission in $\mathrm{ZnO}$ layers could be achieved by deposition of nanocrystalline films which would have a larger band gap due to the quantum confinement effect $[15,16]$.

The literature analysis has shown [17-19] that the substrate temperature has the greatest influence on the sub-structure and optical properties of $\mathrm{ZnO}$ films. In this work, the influence of the substrate temperature on the structural, substructural, and 
some optical properties of the nanocrystalline $\mathrm{ZnO}$ films deposited by pulsed spray pyrolysis was characterized.

\section{Experimental details}

2.1 Synthesis of $\mathrm{ZnO}$ thin films Nanocrystalline $\mathrm{ZnO}$ films were deposited by pulsed spray pyrolysis technique onto cleaned glass substrates in the temperature range of $473-673 \mathrm{~K}$ with $\Delta T=50 \mathrm{~K}$. The temperature control was performed using thermocouple and thermocontroller allowing to adjust the temperature with an accuracy $\pm 5 \mathrm{~K}$. The $0.2 \mathrm{M}$ solution of zinc acetate dihydrate in deionized water was used as the initial precursor. In addition, hydrochloric acid was used to boost the solubility of initial precursor. The air flow with pressure $0.2 \mathrm{MPa}$ was utilized as the carrier gas in order to transport the dispersed precursor onto heated substrate surface. The thickness of condensates was varied in the range of $0.6-1.3 \mu \mathrm{m}$, depending on the substrate temperature. The details of the laboratory setup and the physical and chemical parameters of $\mathrm{ZnO}$ thin film deposition are presented in Ref. [20].

2.2 Substructural properties The structural and substructural properties of $\mathrm{ZnO}$ films were studied by X-ray diffraction analysis using a Bruker D8 with the $K_{\alpha}$ radiation of a Cu anode $(\lambda=0.15406 \mathrm{~nm}, U=40 \mathrm{kV}$, and $I=40 \mathrm{~mA})$. The measurements were carried out in the angle range $2 \theta$ from $20^{\circ}$ to $80^{\circ}$, where $2 \theta$ is the Bragg angle.

The average coherent scattering domain size (CSD) $L$ and the microstrains level $\varepsilon$ in the $\mathrm{ZnO}$ films were determined precisely using the physical broadening of the $\mathrm{X}$-ray lines. The separation of the diffraction broadening caused by the physical $\beta$ and instrumental $b$ effects was performed using the X-ray line profile approximated by the Cauchy and Gauss functions [21, 22].

Subsequently, to allocate the contributions of physical broadening caused by the dispersion of CSDs and microstrains, the graphical Hall method was used, taking into account their different dependences on the diffraction angle. According to this method, the graphics were built in $(\beta \cos \theta / \lambda)^{2}-(4 \sin \theta / \lambda)^{2},(\beta \cos \theta / \lambda)-(4 \sin \theta / \lambda)$ coordinates. The intersection of the straight line with the $x$-axis was used to determine the parameters: $1 / L$, using the Cauchy function for the line profile approximation, and $1 / L^{2}$, using the Gauss function. The microstrains grade can be determined from the slope of the obtained straight line to the $y$-axis [23].

Substructural properties of $\mathrm{ZnO}$ films were studied through the measurements of physical broadening of the two orders of reflection from the crystallographic planes with multiple Miller indices or from planes that are deviated at low angles $\left(<15^{\circ}\right)$. The angle between the planes for a hexagonal lattice is given by the following expression:

$$
\cos \varphi=\frac{h_{1} h_{2}+k_{1} k_{2}+\frac{1}{2}\left(h_{1} k_{2}+h_{2} k_{1}\right)+\frac{3}{4} \frac{a^{2}}{c^{2}} l_{1} l_{2}}{\sqrt{\left[h_{1}^{2}+k_{1}^{2}+h_{1} k_{1}+\frac{3}{4} \frac{a^{2}}{c^{2}} l_{1}^{2}\right]\left[h_{2}^{2}+k_{2}^{2}+h_{2} k_{2}+\frac{3}{4} \frac{a^{2}}{c^{2}} l_{2}^{2}\right]}}
$$

where $\varphi$ is the angle between the investigated planes $\left(h_{1} k_{1} l_{1}\right)$ and $\left(h_{2} k_{2} l_{2}\right)$; and $a$ and $c$ are the lattice parameters of the material.

The microstrains grades and the size of CSDs in the films were found using the threefold convolution method $[24,25]$. In this case, the substructural characteristics of the films can be determined using the following relations [25]:

$$
\begin{aligned}
L & =\frac{\lambda}{\cos \theta_{1}} \cdot \frac{t B_{1}-c B_{2}}{t \beta_{\mathrm{f} 1}^{2}-\beta_{\mathrm{f} 2}^{2}}, \\
\varepsilon^{2} & =\frac{c \beta_{\mathrm{f} 1}^{2} B_{2}-\beta_{\mathrm{f} 2}^{2} B_{1}}{16 \operatorname{tg} \theta_{1}\left(c B_{2}-t B_{1}\right)},
\end{aligned}
$$

where $t=\operatorname{tg}^{2} \theta_{2} / \operatorname{tg}^{2} \theta_{1}, c=\cos \theta_{1} / \cos \theta_{2}, \beta_{\mathrm{fi}}=\sqrt{\left(B_{i}\right)^{2}-\left(b_{i}\right)^{2}}$, $\theta_{1}$ and $\theta_{2}$ are the diffraction angles of the line pair that is being analyzed; and $B_{i}, b_{i}$, and $\beta_{\mathrm{f} i}$ are the measured, instrumental, and physical broadening of the corresponding $\mathrm{X}$-ray lines, respectively.

It should be noted that we defined the broadening $B$ of the diffraction peaks (100)-(200), (101)-(202), and (102)(103) (the angle between planes is $\sim 11^{\circ}$ ) of the hexagonal phase.

The magnitude of the microstresses in the films was determined by the formula $\sigma=E \cdot \varepsilon$, where $E$ is the Young's modulus, which can be found for the hexagonal phase from the relation [17]:

$$
E_{h k l}=\frac{\left[h^{2}+\frac{(h+2 k)^{2}}{3}+\left(\frac{a l}{c}\right)^{2}\right]^{2}}{s_{11}\left(h^{2}+\frac{(h+2 k)^{2}}{3}\right)^{2}+s_{33}\left(\frac{a l}{c}\right)^{4}+\left(2 s_{13}+s_{44}\right)\left(h^{2}+\frac{(h+2 k)^{2}}{3}\right)\left(\frac{a l}{c}\right)^{2}},
$$

where $s_{11}, s_{13}, s_{33}$, and $s_{44}$ are the material malleability constants, $a$ and $c$ are the lattice parameters, and $(h k l)$ are the Miller indices.

In our analysis, we used the following reference data: $s_{11}=7.858 \times 10^{-12}, s_{13}=2.206 \times 10^{-12}, s_{33}=6.940 \times 10^{-12}$, and $s_{44}=23.57 \times 10^{-12} \mathrm{~Pa}^{-1}$ [17]. The lattice parameters $a$ and $c$ were determined experimentally in our previous work [20].

Subsequently, the average dislocation density in $\mathrm{ZnO}$ films was estimated using the calculated CSD sizes and the microstrains grades. The average dislocation density at the subgrain boundaries can be found by the formula [26]:

$$
\rho_{\mathrm{L}}=\frac{3 n}{L^{2}},
$$

where $n$ is the number of dislocations on each face of the six planes of the CSD block.

If the dislocations are mostly located inside the subgrains, the dislocation density can be obtained from the expression [26]

$$
\rho_{\varepsilon}=\frac{K}{F}\left(\frac{2 \varepsilon}{d_{0}}\right)^{2},
$$


where $K$ is the constant depending on the dislocation distribution function ( $K=4$ for the Gauss function, $K=25$ for the Cauchy function), $2 \varepsilon$ is the width of the microstrains distribution, $F$ is the constant, taking into account the increased dislocation energy under interaction with other dislocations, and $d_{0}$ is the interplanar distance.

Assuming $n=1$ and $F=1$, Eq. (5) allows to estimate the lowest limit of the dislocation density $\rho_{\mathrm{L}}$, and Eq. (6) the highest limit of $\rho_{\varepsilon}$. To determine the total dislocation density, including the dislocations at the subgrains and the inside of CSD blocks, we used the relation [26]

$$
\rho=\frac{15 \varepsilon}{d_{0} L} .
$$

2.3 Raman and FTIR spectroscopies The Raman measurements were performed at room temperature using a confocal Raman microscope (WiTec Alpha 300). This device was equipped with an excitation laser with a wavelength of $532 \mathrm{~nm}$ and intensity of $1 \mathrm{~mW}, 600$ lines $\mathrm{mm}^{-1}$ gratings, an optical fiber with diameter of $100 \mathrm{~nm}$, and a Nikon objective with a $100 \times$ magnification. The measurements were carried out in the spectral range from 80 up to $800 \mathrm{~cm}^{-1}$. The Raman imaging of the samples was performed over a $10 \times 10 \mu \mathrm{m}^{2}$ area with a step of $200 \mathrm{~nm}$ for the Raman peak at $437 \mathrm{~cm}^{-1}$.

The FTIR spectra were recorded using an Agilent Cary 630 FTIR spectrometer in the range of $400-4000 \mathrm{~cm}^{-1}$ with a spectral resolution of $1 \mathrm{~cm}^{-1}$. The method of light reflection was applied for measurements which allowed using conventional glass substrates with deposited $\mathrm{ZnO}$ films. The penetration depth of infrared radiation into the films was $\sim 0.9 \mu \mathrm{m}$.

\section{Results and discussion}

3.1 Substructural properties of $\mathrm{ZnO}$ films As we reported in previous work [20], $\mathrm{ZnO}$ films had the polycrystalline structure of the hexagonal modification with the grain size in the range of $20-300 \mathrm{~nm}$, revealing the nanocrystalline nature. The films were grown along the axial texture [100] at $T_{\mathrm{s}} \leq 573 \mathrm{~K}$ and [002] at $T_{\mathrm{s}}>573 \mathrm{~K}$. The experimental values of the lattice parameters of the material were determined as $a=0.32477-0.32554 \mathrm{~nm}, c=0.51507$ $0.52111 \mathrm{~nm}$, and their ratio $c / a=1.5822-1.6046$.

The calculated results of the average size of CSDs and the microstrains grades in $\mathrm{ZnO}$ films, deposited at different substrate temperatures $T_{\mathrm{s}}$, in the perpendicular directions to the crystallographic planes (100)-(200), (101)-(202), and (102)-(103) are summarized in Table 1. Figure 1 shows the obtained values using the threefold convolution method in the perpendicular directions to the planes specified above.

It should be noted that the calculated size of CSDs and the microstrain values in $\mathrm{ZnO}$ films using the threefold convolution method fall between the data obtained using the approximation of X-ray lines by the Cauchy and Gaussian functions, as it must be on the theoretical considerations. It indicates the validity of the obtained results from the analysis of X-ray line broadening.

As the substructural parameters of the films determined by the threefold convolution method are the most accurate, the following discussion and supplemental calculations of the microstresses grades and the density of dislocation were performed using them.

One can be seen from Table 1 and Fig. 1a that as the substrate temperature is increased from 473 to $673 \mathrm{~K}$, the size of CSDs tends to increase: from $L \sim 14$ up to $23 \mathrm{~nm}$ in the [100] direction, from $L \sim 11$ up to $\sim 20 \mathrm{~nm}$ in the [101] direction, and from $L \sim 10$ up to $\sim 63 \mathrm{~nm}$ in the [102]

Table 1 The size of CSDs $(L)$ and the microstrains grades $(\varepsilon)$ of $\mathrm{ZnO}$ films deposited at different substrate temperatures.

\begin{tabular}{|c|c|c|c|c|c|c|c|}
\hline \multirow[b]{3}{*}{$T_{\mathrm{s}}(\mathrm{K})$} & \multirow[b]{3}{*}{$(h k l)$} & \multicolumn{3}{|l|}{$L(\mathrm{~nm})$} & \multicolumn{3}{|c|}{$\varepsilon \cdot\left(10^{-3}\right)$} \\
\hline & & \multicolumn{2}{|c|}{ approximation function } & \multirow[b]{2}{*}{ convolution } & \multicolumn{2}{|c|}{ approximation function } & \multirow[b]{2}{*}{ convolution } \\
\hline & & Gauss & Cauchy & & Gauss & Cauchy & \\
\hline \multirow[t]{3}{*}{473} & $(100)-(200)$ & 13.8 & 15.0 & 13.9 & 0.010 & 1.270 & 0.016 \\
\hline & (101)-(202) & 11.1 & 11.0 & 11.1 & 0.001 & 0.080 & 0.007 \\
\hline & (102)-(103) & 9.4 & 9.6 & 10.0 & 0.004 & 0.440 & 0.006 \\
\hline \multirow[t]{3}{*}{523} & $(100)-(200)$ & 13.1 & 13.4 & 13.1 & 0.003 & 0.410 & 0.009 \\
\hline & (101)-(202) & 10.8 & 11.9 & 10.9 & 0.014 & 1.650 & 0.035 \\
\hline & $(102)-(103)$ & 9.4 & 10.1 & 10.0 & 0.012 & 1.230 & 0.010 \\
\hline \multirow[t]{3}{*}{573} & (100)-(200) & 18.5 & 20.8 & 18.6 & 0.008 & 1.360 & 0.011 \\
\hline & (101)-(202) & 11.8 & 10.1 & 11.9 & 0.014 & 2.420 & 0.027 \\
\hline & (102)-(103) & 9.2 & 9.3 & 9.9 & 0.001 & 0.080 & 0.003 \\
\hline \multirow[t]{3}{*}{623} & $(100)-(200)$ & 22.3 & 25.3 & 22.5 & 0.006 & 1.170 & 0.008 \\
\hline & $(101)-(202)$ & 16.4 & 13.2 & 16.7 & 0.009 & 2.420 & 0.015 \\
\hline & (102)-(103) & 12.4 & 10.8 & 13.5 & 0.011 & 1.890 & 0.007 \\
\hline \multirow[t]{3}{*}{673} & $(100)-(200)$ & 20.6 & 21.2 & 20.6 & 0.001 & 0.320 & 0.005 \\
\hline & $(101)-(202)$ & 18.2 & 13.4 & 19.1 & 0.010 & 3.210 & 0.012 \\
\hline & $(102)-(103)$ & 39.0 & 101.1 & 62.3 & 0.027 & 4.830 & 0.007 \\
\hline
\end{tabular}



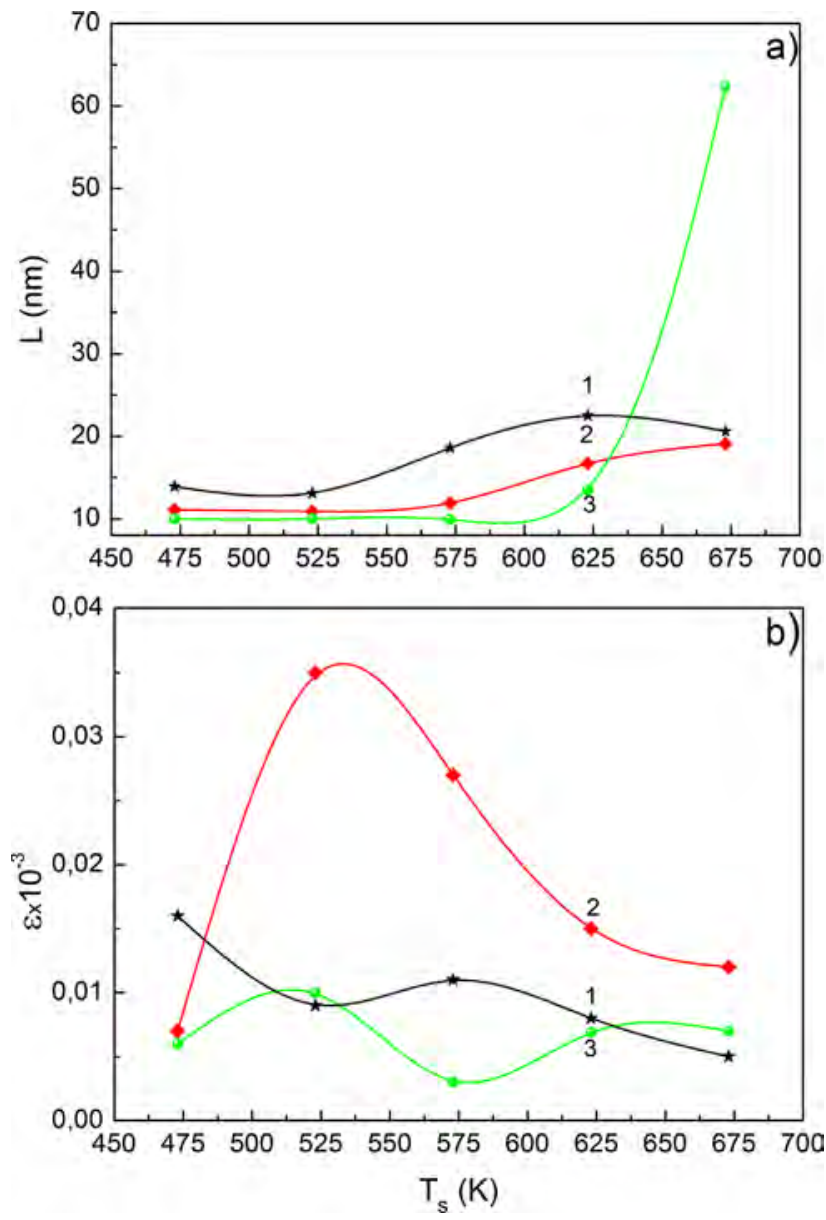

Figure 1 Effect of the substrate temperatures $T_{\mathrm{s}}$ on (a) the size of CSDs and (b) the microstrain grades of $\mathrm{ZnO}$ films in the perpendicular direction to the crystallographic planes (100)-(200) (1), (101)-(202) (2), (102)-(103) (3). The threefold convolution method was used for approximation.

direction. We have observed similar dependences of $L$ versus $T_{\mathrm{S}}$ in Ref. [27] for compounds CdTe, $\mathrm{ZnS}, \mathrm{ZnSe}$, and ZnTe obtained by closed space vacuum sublimation.

At the same time, the microstrain grades in $\mathrm{ZnO}$ films in the [100] direction was decreasing from $\varepsilon \sim 1.6 \times 10^{-5}$ to $\sim 0.5 \times 10^{-5}$, in the [101] direction from $\varepsilon \sim 3.5 \times 10^{-5}$ to $\sim 1.2 \times 10^{-5}$, and in the [102] direction from $\varepsilon \sim 1.0 \times 10^{-5}$ to $\sim 0.7 \times 10^{-5}$ (Fig. 1b). A similar reduction in $\varepsilon$ was observed in thin films of $\mathrm{CdTe}$ and $\mathrm{ZnTe}$ at substrate temperatures $T_{\mathrm{s}}>573 \mathrm{~K}[27,28]$. It should be mentioned that the calculated values of microstrains in $\mathrm{ZnO}$ films are significantly lower than the values obtained in Ref. [18], where $\mathrm{ZnO}$ films were deposited by the spray pyrolysis method at $T_{\mathrm{s}}=673 \mathrm{~K}$ with a different concentration of zinc acetate dihydrate $(0.05-0.15 \mathrm{M})$. The authors found that the microstrains grades in $\mathrm{ZnO}$ films was in the range of $\varepsilon=(3.7-5.8) \times 10^{-4}$ in the [100] direction.

Using the calculated values of microstrains, we have defined the microstress levels in the nanocrystalline $\mathrm{ZnO}$
Table 2 The microstress levels and the density of dislocations in the $\mathrm{ZnO}$ films.

\begin{tabular}{llllll}
\hline $\begin{array}{l}T_{\mathrm{s}} \\
(\mathrm{K})\end{array}$ & $(h k l)$ & $\begin{array}{l}\sigma \\
(\mathrm{MPa})\end{array}$ & $\begin{array}{l}\rho_{\mathrm{L}} \\
\left(10^{12} \text { lines m }^{-2}\right)\end{array}$ & $\begin{array}{l}\rho_{\varepsilon} \\
\left(10^{11} \text { lines } \mathrm{m}^{-2}\right)\end{array}$ & $\begin{array}{l}\rho\left(10^{13}\right. \\
\left.\text { lines } \mathrm{m}^{-2}\right)\end{array}$ \\
\hline 473 & $(100)$ & 1.53 & 1.6 & 2.1 & 6.1 \\
523 & $(100)$ & 0.86 & 1.7 & 0.6 & 3.6 \\
573 & $(100)$ & 1.05 & 0.9 & 1.0 & 3.2 \\
623 & $(100)$ & 0.76 & 0.6 & 0.5 & 1.9 \\
673 & $(100)$ & 0.48 & 0.7 & 0.2 & 1.3 \\
\hline
\end{tabular}

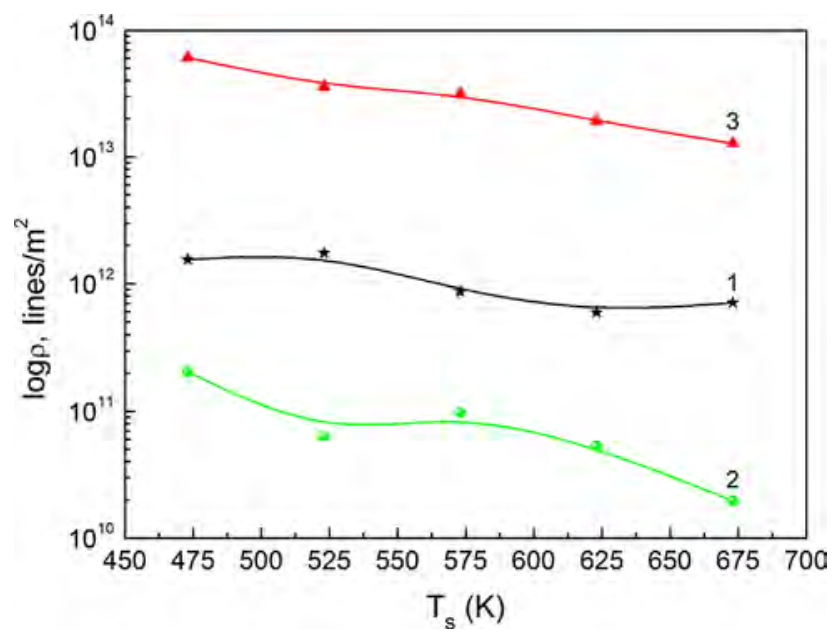

Figure 2 The effect of substrate temperature $T_{\mathrm{s}}$ on (1) the density of dislocations in $\mathrm{ZnO}$ films at the boundaries of subgrains, (2) inside the CSD blocks, and (3) the total concentration of dislocations in the perpendicular direction to the planes (100)(200).

films (Table 2). It was found that the microstress levels in the thin films were $\sigma=0.48-1.53 \mathrm{MPa}$. Significantly higher values of $\sigma$ were obtained by Rao et al. in Refs. [29, 30]. The authors found that with increasing $T_{\mathrm{s}}$ from 623 to $723 \mathrm{~K}$, the compressive stress levels decrease from 1.77 to $1.47 \mathrm{GPa}$.

Table 2 and Fig. 2 show the calculated results of the dislocations at the boundaries of subgrains $\left(\rho_{\mathrm{L}}\right)$ and inside CSD blocks $\left(\rho_{\varepsilon}\right)$, and the total concentration $(\rho)$ in $\mathrm{ZnO}$ films in the perpendicular direction to the (100) plane.

Similar investigations were carried out by authors of Refs. [18, 31]. Shewale et al. [31] determined that in nanocrystalline $\mathrm{ZnO}$ films with the thickness $d=0.135$ $0.392 \mu \mathrm{m}$, deposited at $T_{\mathrm{s}}=473 \mathrm{~K}$, the concentration of dislocations was in the range of $\rho=(1.29-4.15) \times$ $10^{15}$ lines $\mathrm{m}^{-2}$.

The authors of Ref. [18] obtained the values of $\rho$ $=(2.4-5.8) \times 10^{13}$ lines $\mathrm{m}^{-2}$. As can be seen in comparison with the results obtained by other authors, the films in this work are characterized by relatively low values of $\rho=(1.3$ $-6.1) \times 10^{13}$ lines $\mathrm{m}^{-2}$. As shown in Fig. 2 , the increase of $T_{\mathrm{s}}$ tends to decrease $\rho$ in $\mathrm{ZnO}$ layers. 

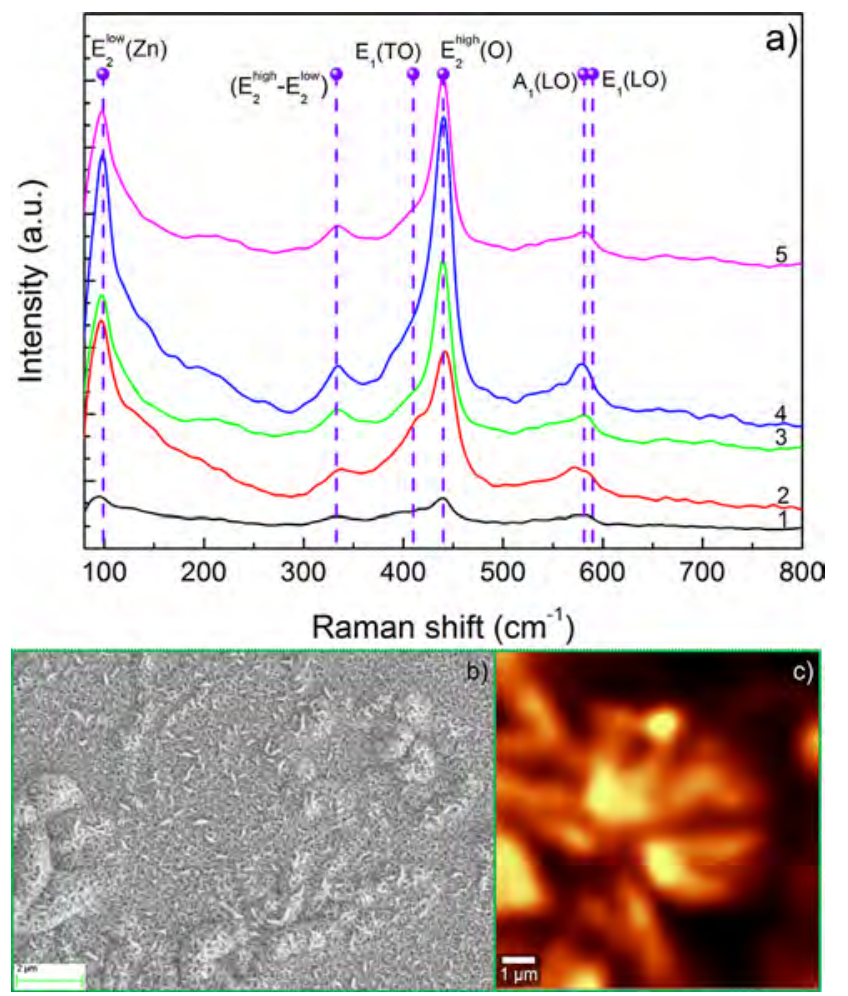

Figure 3 (a) Raman spectra of $\mathrm{ZnO}$ films deposited at different substrate temperatures, $T_{\mathrm{s}}$ : 473 (1), 523 (2), 573 (3), 623 (4), $673 \mathrm{~K}$ (5). (b) SEM images, and (c) Raman mapping of $\mathrm{ZnO}$ film surface deposited at $T_{\mathrm{s}}=673 \mathrm{~K}$.

3.2 Raman spectroscopy Raman spectroscopy is a powerful technique used to study the chemical composition and the quality of the crystal structure of semiconductor compounds. The Raman spectra of $\mathrm{ZnO}$ films, measured in the frequency region from 80 to $800 \mathrm{~cm}^{-1}$, are shown in Fig. 3a.

As seen in Fig. 3a and Table 3, a series of phonon peaks are observed at the frequencies around 95-98, 333-336, $415,439-442,572$, and $578-584 \mathrm{~cm}^{-1}$. According to the literature, these peaks are interpreted as $E_{2}{ }^{\text {low }}(\mathrm{Zn})[32,34]$, $E_{2}^{\text {high }}-E_{2}{ }^{\text {low }}$ [32-34], $E_{1}(\mathrm{TO})$ [32, 34], $E_{2}{ }^{\text {high }}(\mathrm{O})$ [7, 32-34], $A_{1}(\mathrm{LO})$ [33], and $E_{1}(\mathrm{LO})[7,32]$ phonon modes. The two $E_{2}$ modes are the most prominent in the spectra: the $E_{2}$ high peak, attributed to the oxygen anions, is located at $439-442 \mathrm{~cm}^{-1}$, and the $E_{2}{ }^{\text {low }}$ peak, attributed to zinc cations, is located at $95-98 \mathrm{~cm}^{-1}$.

It is known [35] that the crystal quality of $\mathrm{ZnO}$ films has a direct influence on the intensity of the $E_{2}$ modes. Furthermore, the $E_{2}{ }^{\text {high }}(\mathrm{O})$ peak is exceedingly sensitive to the presence of internal defects in the material [34]. The frequency deviation of the $E_{2}{ }^{\text {high }}(\mathrm{O})$ peak from values in the bulk material $\left(437 \mathrm{~cm}^{-1}\right)$ is evidence for the presence of microstresses and crystal lattice defects in the material. In our case, it is worth to note that as the substrate temperature increases, the position of $E_{2}{ }^{\text {high }}(\mathrm{O})$ peak shifts from 442 to $439 \mathrm{~cm}^{-1}$, indicating decrease of $\sigma$ and $\rho$. These statements
Table 3 The peak assignments from the Raman spectra of $\mathrm{ZnO}$ films deposited at different substrate temperatures.

experimental data

\begin{tabular}{|c|c|c|c|c|}
\hline 473 & 523 & 573 & 623 & 673 \\
\hline \multicolumn{5}{|c|}{ Raman shift $\left(\mathrm{cm}^{-1}\right)$} \\
\hline 95 & 97 & 97 & 98 & 97 \\
\hline 334 & 336 & 333 & 334 & 334 \\
\hline- & 415 & - & - & - \\
\hline 441 & 442 & 440 & 439 & 439 \\
\hline- & 572 & - & - & 572 \\
\hline 578 & 584 & 582 & 579 & 582 \\
\hline
\end{tabular}

literature data

\begin{tabular}{lll}
\hline Raman shift $\left(\mathrm{cm}^{-1}\right)$ & mode & ref. \\
\hline 99 & $E_{2}^{\text {low }}(\mathrm{Zn})$ & {$[32,34]$} \\
333 & $\left(E_{2}^{\text {high }}-E_{2}^{\text {low }}\right)$ & {$[32-34]$} \\
410 & $E_{1}(\mathrm{TO})$ & {$[32,34]$} \\
438 & $E_{2}^{\text {high }}(\mathrm{O})$ & {$[7,32-34]$} \\
570 & $A_{1}(\mathrm{LO})$ & {$[33]$} \\
579 & $E_{1}(\mathrm{LO})$ & {$[7,32]$} \\
\hline
\end{tabular}

are consistent with the preceding calculations from X-ray analysis. Figure 3(b and c) shows representative scanning electron microscopy (SEM) micrographs and the results of the confocal Raman mapping of the $\mathrm{ZnO}$ film surface at $T_{\mathrm{s}}=673 \mathrm{~K}$.

The image was constructed from the integrated intensity in the frequency range of $437 \pm 20 \mathrm{~cm}^{-1}$ at each point of the sample. As already indicated, this frequency corresponds to the $E_{2}{ }^{\text {high }}(\mathrm{O})$ mode of $\mathrm{ZnO}$. To increase the contrast of the image, an offset in the intensity value was introduced.

Figure $3 \mathrm{~b}$ shows hills on the surface of the film which coincide with the boundaries of precursor droplets that were pyrolyzed after the contact with the hot substrate. Other than that, the surface is mostly quite smooth.

The micro-Raman imaging of the surface near the footprint of a drop is depicted in Fig. 3c. The bright areas correspond to the largest peak intensity of $437 \mathrm{~cm}^{-1}$ with the highest offset with respect to the position of bulk material, which indicates the local microstresses in structures. Unfortunately, it was almost impossible to carry out the measurements on the same area of the film surface by using these methods, and so the investigated regions shown in Fig. $3 b$ and $c$ are not the same.

3.3 FTIR spectroscopy Fourier transform infrared spectroscopy (FTIR) is a complementary technique to XRD and Raman techniques for investigating chemical composition and vibrational properties in material science. The frequencies at which there is absorption or transmission of light in the films provide an opportunity to identify the functional bands of chemical elements which are present in the samples. Particularly, often this approach is used to 

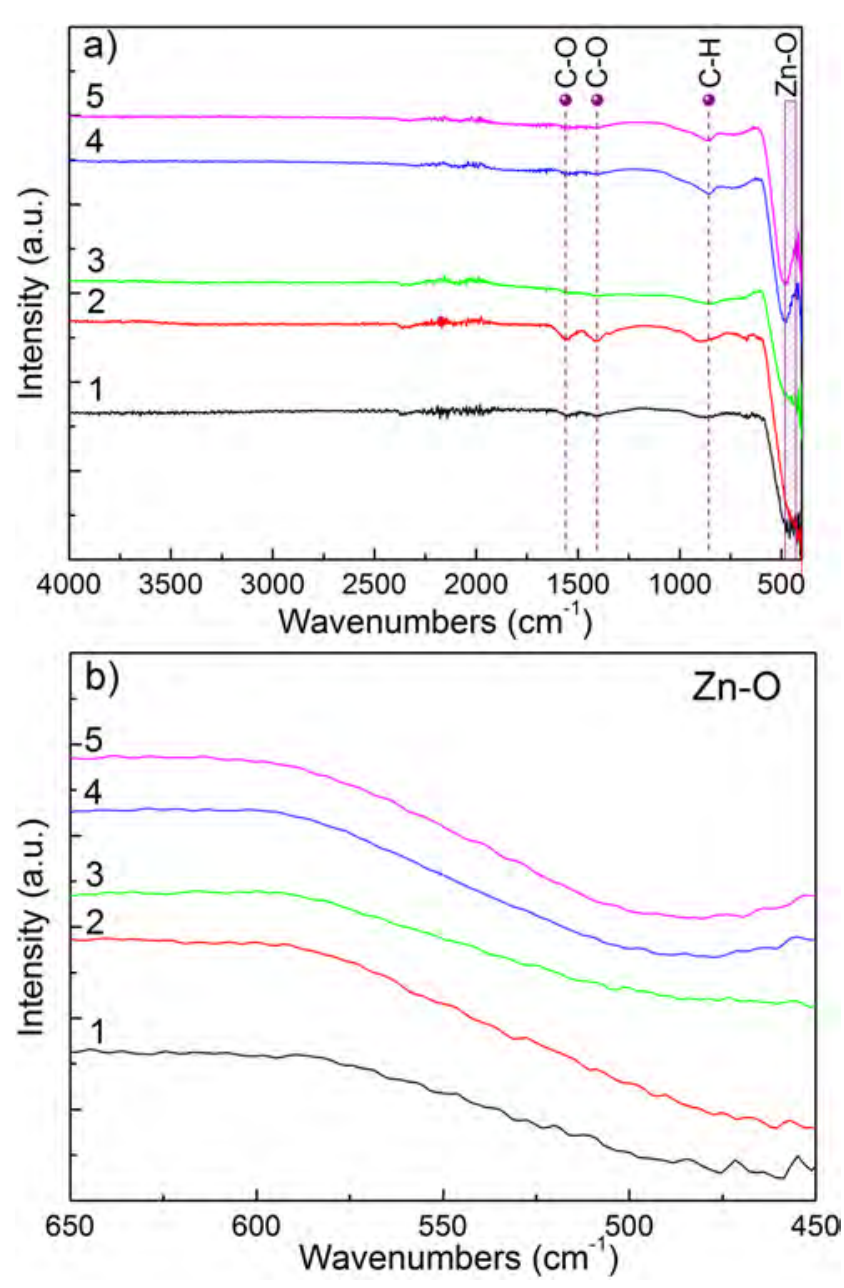

Figure 4 FTIR spectra of $\mathrm{ZnO}$ films deposited at different substrate temperatures $T_{\mathrm{s}}$ : 473 (1), 523 (2), 573 (3), 623 (4), $673 \mathrm{~K}$ (5) for whole measured range (a), and extended peak for $\mathrm{Zn}--\mathrm{O}$ vibration mode (b).

detect residual elements of precursors in films obtained by chemical methods [36, 37].

Figure 4 shows the reflection FTIR spectra of $\mathrm{ZnO}$ films obtained at different substrate temperatures. Despite the fact that the films were obtained by a chemical method, the infrared reflectance spectra are quite "clean" for $\mathrm{ZnO}$ films deposited at $T_{\mathrm{s}}>573 \mathrm{~K}$. In the low-frequency region of 460 $475 \mathrm{~cm}^{-1}$, the reflectance minimum similar to the data in the literature [37-39] is attributed to the $\mathrm{Zn}-\mathrm{O}$ vibration mode (Fig. 4b). It is important to note that the obtained spectra of the films deposited at the whole range of substrate temperatures contained the $\mathrm{C}-\mathrm{H}$ (at around $850 \mathrm{~cm}^{-1}$ ) vibration mode [39]. It should be noted, that this peak was observed in the whole substrate temperature range and with the increase of $T_{\mathrm{s}}$ it becomes narrower. It indicates that even at high-substrate temperatures the residuals of relevant impurities were remained in the films. Noteworthy, FTIR spectroscopy is a very sensitive to the footprints of residual impurities.
The bands at 1405 and $1560 \mathrm{~cm}^{-1}$ can be ascribed to the $\mathrm{C}-\mathrm{O}$ symmetric and asymmetric stretching vibrations in the $\mathrm{ZnO}$ films deposited at $T_{\mathrm{s}}<573 \mathrm{~K}$ [37]. The absence of these modes at $T_{\mathrm{s}}>573 \mathrm{~K}$ indicates decomposition of the precursor at the substrate surface and low probability for the existence of the elements from acetate groups at the $\mathrm{ZnO}$ surface during the pyrolysis process that promotes the formation of single-phase zinc oxide films. Furthermore, no other bands corresponding to $\mathrm{O}-\mathrm{H}$ stretching modes were observed. It indicates a low concentration of impurities and relatively high-chemical purity of the studied films [40].

4 Conclusions In this work, nanocrystalline $\mathrm{ZnO}$ films were deposited onto glass substrates at the substrate temperatures from 473 to $673 \mathrm{~K}$. The average size of CSDs, microstrains grades, microstress levels, and the density of dislocations in the $\mathrm{ZnO}$ films were determined by means of $\mathrm{X}$-ray diffraction analysis. Moreover, the chemical composition and crystal quality of the $\mathrm{ZnO}$ films were investigated using Raman and FTIR spectroscopies.

It was shown that the highest values of CSDs in $\mathrm{ZnO}$ films deposited at the substrate temperatures range of $623-673 \mathrm{~K}$ were $21-23 \mathrm{~nm}$ in the perpendicular directions to the (100)-(200) planes, $17-20 \mathrm{~nm}$ for the (101)-(202) planes, and $14-63 \mathrm{~nm}$ for the (102)-(103) planes. When $T_{\mathrm{s}}$ increased, the microstrains and microstress levels in the films decreased from $\varepsilon \sim 1.6 \times 10^{-5}$ to $\sim 0.5 \times 10^{-5}$ ( $\sigma$ from 1.53 to $0.48 \mathrm{MPa}$ ) in the perpendicular direction to the (100) plane. The $\mathrm{ZnO}$ films are characterized by the low values of dislocation density $\rho=(1.3-6.1) \times 10^{13}$ lines $^{-2}$.

Raman spectra of the films show two strong phonon modes $\left(E_{2}{ }^{\text {high }}(\mathrm{O})\right.$ and $\left.E_{2}{ }^{\text {low }}(\mathrm{Zn})\right)$. In addition, $\left(E_{2}{ }^{\text {high }}\right.$ $\left.E_{2}^{\text {low }}\right), E_{1}(\mathrm{TO}), A_{1}(\mathrm{LO})$, and $E_{1}(\mathrm{LO})$ phonon modes were observed. Furthermore, the FTIR spectroscopy showed the bands related to $\mathrm{Zn}-\mathrm{O}$ and $\mathrm{C}-\mathrm{H}$ stretching modes for the entire substrate temperature range. No $\mathrm{C}-\mathrm{O}$ vibration modes were observed in the spectra of the $\mathrm{ZnO}$ films deposited at $T_{\mathrm{s}}>573 \mathrm{~K}$. It clearly attests to the complete decomposition of initial solution at the substrate surface and the lack of the acetate group elements in the high-temperatures $\mathrm{ZnO}$ films.

The above results show that the substrate temperature has a great effect on the composition, substructural, and optical properties of $\mathrm{ZnO}$ films using a pulsed spray pyrolysis. It can be concluded that the temperature range of $623-673 \mathrm{~K}$ is the most suitable to obtain single phase $\mathrm{ZnO}$ films with a relatively large CSDs, low microstrains, microstresses, and dislocation density for applications in optoelectronic devices.

Acknowledgements This work was supported by Ministry of Education and Science of Ukraine (Grant No. 0113U000131, No. 0115U003242) and individual grant for D.O.).

\section{References}

[1] A. Janotti and C. G. Van de Walle, Rep. Prog. Phys. 72, 126501 (2009).

[2] J. C. Fan, S. L. Chang, and Z. Xie, in: ZnO-based LightEmitting Diodes, Optoelectronics - Advanced Materials and 
Devices, edited by S. Pyshkin (InTech, Rijeka, Croatia, DOI: 10.5772/51181, ISBN: 978-953-51-0922-8), available from: http://www.intechopen.com/books/optoelectronicsadvanced-materials-and-devices/zno-based-light-emittingdiodes.

[3] D. Hofstetter, Y. Bonetti, F. R. Giorgetta, A.-H. El-Shaer, A. Bakin, A. Waag, R. Schmidt-Grund, M. Schubert, and M. Grundmann, Appl. Phys. Lett. 91, 111108 (2007).

[4] S. Bai, W. Wu, Y. Qin, N. Cui, D. J. Bayerl, and X. Wang, Adv. Funct. Mater. 21, 4464 (2011).

[5] K. Ellmer, A. Klein, and B. Rech, Transparent Conductive Zinc Oxide: Basics and Applications in Thin Film Solar Cells (Springer-Verlag, Berlin, Heidelberg, Berlin, 2008), p. 446.

[6] U. Ozgur, Ya. I. Alivov, C. Liu, A. Teke, M. A. Reshchikov, S. Dogan, V. Avrutin, S.-J. Cho, and H. Morkoc, J. Appl. Phys. 98, 041301 (2005).

[7] J. G. Lum, T. Kawaharamura, H. Nishinaka, Y. Kamada, T. Ohshima, and S. Fujita, J. Cryst. Growth 299, 1 (2007).

[8] W. Gao and Z. Li, Ceram. Int. 30, 1155 (2004).

[9] L. Znaidi, Mater. Sci. Eng. B 174, 18 (2010).

[10] K. Krunks, O. Bijakina, V. Mikli, T. Varema, and E. Melliko, Phys. Scripta 1999, 209 (1999).

[11] J. L. van Heerden and R. Swanepoel, Thin Solid Films 299, 72 (1997).

[12] N. L. Tarwal, A. V. Rajgure, A. I. Inamdat, R. S. Devan, I. Y. Kim, S. S. Suryavanshi, Y. R. Ma, J. H. Kim, and P. S. Patil, Sensor. Actuators A 199, 67 (2013).

[13] H. Bayhan and M. Bayhan, Sol. Energy 87, 168 (2013).

[14] H. Zhu, J. Hupkes, E. Bunte, and S. M. Huang, Appl. Surf. Sci. 261, 268 (2012).

[15] H. L. Ma, Z. W. Liu, D. C. Zeng, M. L. Zhong, H. Y. Yu, and E. Mikmekova, Appl. Surf. Sci. 283, 1006 (2013).

[16] G. K. Mani and J. B. B. Rayappan, Superlatticees Microstruct. 67, 82 (2014).

[17] V. D. Mote, Y. Purushotham, and B. N. Dole, J. Theor. Appl. Phys. 6, 6 (2012).

[18] R. Mariappan, V. Ponnuswamy, and M. Ragavendar, Mater. Sci. Semicond. Process. 16, 1328 (2013).

[19] L. C. Nehru, M. Umadevi, and C. Sanjeeviraja, Int. J. Mater. Eng. 2, 12 (2012).

[20] O. Dobrozhan, D. Kurbatov, A. Opanasyuk, H. Cheong, and A. Cabot, Surf. Interface Anal. 47, 601 (2015).

[21] A. Opanasyuk, V. V. Kosyak C. J. Panchal, M. S. Desai, and I. Yu. Protsenko, J. Nano Electron. Phys. 3, 274 (2011).

[22] D. K. Bowen and B. K. Tanner, X-ray Metrology in Semiconductor Manufacturing (Taylor \& Francis Group, London, 2006), p. 296.
[23] L. S. Palatnik, Structure and Physical Properties of Solid State (Vyssha shkola, Kyiv, 1983), p. 264 (in Russian).

[24] D. Kurbatov, V. Kosyak, M. Kolesnyk, A. Opanasyuk, and S. Danilchenko, Integr. Ferroelectr. 103, 32 (2008).

[25] A. S. Kagan, L. M. Syshlyannikova, and A. P. Unikel, Zavod. Lab. 46, 903 (1980).

[26] L. S. Palatnik, M. Ya Fuks, and V. M. Kosevich, Mechanism of Self-Formation and Substructure of Condensed Films (Nauka, Moscow, 1972), p. 319 (in Russian).

[27] A. S. Opanasyuk, D. I. Kurbatov, V. V. Kosyak, S. I. Kshniakina, and S. N. Danilchenko, Crystallogr. Rep. 57, 927 (2012).

[28] V. Kosyak, A. Opanasyuk, P. M. Bukivskij, and Yu. P. Gnatenko, J. Cryst. Growth 312, 1726 (2010).

[29] T. Prasada Rao, M. C. Santhosh Kumar, S. Anbumozhi Angayarkanni, and M. Ashok, J. Alloys Compd. 485, 413 (2009).

[30] T. Prasada Rao, M. C. Santhosh Kumar, A. Safarulla, V. Ganesan, S. R. Barman, and C. Sanjeeviraja, Physica B 405, 2226 (2010)

[31] P. S. Shewale, G. L. Agawane, S. W. Shin, A. V. Moholkar, J. Y. Lee, J. H. Kim, and M. D. Uplane, Sens. Actuators B 177, 695 (2013).

[32] J. S. Bendall, G. Visimberga, M. Szachowicz, N. O. V. Plank, S. Romanov, C. M. Sotomayor-Torres, and M. E. Welland, J. Mater. Chem. 18, 5259 (2008).

[33] A. El Manouni, F. J. Manjon, M. Mollar, B. Mari, R. Gomez, M. C. Lopez, and J. R. Ramos-Barrado, Superlattices Microstruct. 39, 185 (2006).

[34] A. Bedia, F. Z. Bedia, M. Aillerie, N. Maloufi, S. Ould, Saad, Hamady, O. Perroud, and B. Benyoucef, Opt. Mater. 36, 1123 (2014).

[35] Z. Li, Z. Hu, F. Liu, H. Hang, X. Zhang, Y. Wang, L. Jiang, P. Yin, and L. Guo, Opt. Mater. 34, 1908 (2012).

[36] H. Khallaf, G. Chai, O. Lupan, H. Heinrich, S. Park, A. Schulte, and L. Chow, J. Phys. D, Appl. Phys. 42, 135304 (2009).

[37] Z. R. Khan, M. S. Khan, M. Zulfequar, and M. S. Khan, Mater. Sci. Appl. 2, 340 (2011).

[38] A. Djelloul, M.-S. Aida, and J. Bougdira, J. Lumin 130, 2113 (2010).

[39] G. Socrates, Infrared and Raman Characteristic Group Frequencies: Tables and Charts (John Willey and Sons, Chichester, 2004), p. 347.

[40] I. Stambolova, V. Blaskov, M. Shipochka, S. Vassilev, V. Petkova, and A. Loukanov, Mater. Sci. Eng. B 177, 1029 (2012). 